\title{
Alpine Entomology: The journal of the Swiss Entomological Society (SES) goes alpine
}

\author{
Thibault Lachat ${ }^{1,2}$, Hannes Baur ${ }^{3,4}$ \\ 1 Bern University of Applied Sciences BFH, School of Agricultural, Forest and Food Sciences HAFL, Zollikofen, Switzerland \\ 2 Swiss Federal Institute for Forest, Snow and Landscape Research, WSL, Birmensdorf, Switzerland \\ 3 Natural History Museum, Bern, Switzerland \\ 4 University of Bern, Institute of Ecology and Evolution, Baltzerstrasse, Bern, Switzerland \\ http://zoobank.org/3DA0F045-7AD5-4956-9B47-E7ABB40A9ED6
}

Corresponding author: Thibault Lachat (thibault.lachat@bfh.ch)

The Mitteilungen der Schweizerischen Entomologischen Gesellschaft have been published since 1862. For 155 years, the Journal of the Swiss Entomological Society published articles from around the world in all fields of entomology. At the general assembly in March of this year, the Swiss Entomological Society unanimously decided to break with this tradition and to set out in a novel direction with a new focus and format. The new journal is entitled Alpine Entomology.

The new title comes not by chance, since a large part of Switzerland is mountainous and much of the European Alpine region is found inside the country. Beginning with this issue, the Swiss Entomological Society is relaunching the journal to provide an international forum for studies on insects and occasionally other arthropods from Alpine and other mountain regions all over the world. Focusing the scope will improve the quality of the journal and of the submitted papers and therefore increase the impact in the scientific community.

Our definition of mountainous regions follows the one proposed by Körner et al. (2011), which is based on ruggedness of the landscape rather than on elevation. Following this definition, more than $12.3 \%$ of all terrestrial land area can be considered mountainous. In Switzerland, the proportion of mountainous terrain reaches $80 \%$. Many articles published in recent years in the Mitteilungen would thus have qualified for publication in Alpine Entomology because their subject matter was in keeping with the journal's new focus.
As in the past, Alpine Entomology will promote the publication of entomological studies from members of the Swiss Entomological Society. The SES covers the open-access fee for all members for up to 10 pages per year when they are either first or corresponding author. Alpine Entomology remains a multilingual journal. The journal primarily publishes articles in English; however, manuscripts in German, French and Italian are also welcome, provided they contain an English abstract.

Not only have the scope and focus of the journal been adjusted but the entire editing process has also been revised. Alpine Entomology has been transferred to Pensoft Publishers. The new publisher offers a web platform that will greatly increase the journal's visibility for the scientific community. Furthermore, all articles published in the journal are open access. Consequently, the articles become freely available to practically everyone. The transfer to Pensoft also implies new submission and review processes, in accordance with the standards of modern scientific publishing.

Alpine Entomology is available both online and in print. This is also the case for all volumes of the Mitteilungen, which have been digitalised and are freely available online in PDF format through the e-periodica portal of the ETH Bibliothek. Members of the Swiss Entomological Society receive a printed copy of the year's volume of the new journal. The first volume of Alpine Entomology includes the articles accepted for publication in this year's Mitteilungen, as well as addi- 
tional articles specifically submitted to the new journal. You will also find an acknowledgement for Gerhard Bächli, prior managing editor of the Mitteilungen, and best wishes for Ivan Löbl, as well as the annual report of the society.

We are enthusiastic about launching the new journal "Alpine Entomology". We will work hard to make it a major resource for researchers dealing with insect sciences in mountain regions. We hope you will all take advantage of this new journal by both reading and publishing within Alpine Entomology. We invite you all to take part in this alpine endeavor for our new journal.

Körner C, Paulsen J, Spehn EM (2011) A definition of mountains and their bioclimatic belts for global comparisons of biodiversity data. Alp Botany 121:73-78. https://doi.org/10.1007/s00035-011-0094-4 